\title{
Anti-HER2 IgY antibody-functionalized single-walled carbon nanotubes for detection and selective destruction of breast cancer cells
}

\author{
Yan Xiao*1, Xiugong Gao ${ }^{\dagger 2}$, Oleh Taratula ${ }^{\dagger 3}$, Stephen Treado ${ }^{\dagger 4}$, \\ Aaron Urbas ${ }^{1}$, R David Holbrook ${ }^{1}$, Richard E Cavicchi ${ }^{1}, \mathrm{C}$ \\ Thomas Avedisian ${ }^{5}$, Somenath Mitra ${ }^{6}$, Ronak Savla ${ }^{3}$, Paul D Wagner ${ }^{7}$, \\ Sudhir Srivastava ${ }^{7}$ and Huixin $\mathrm{He}^{* 3}$
}

\begin{abstract}
Address: ${ }^{1}$ Chemical Science and Technology Laboratory, National Institute of Standards and Technology (NIST), Gaithersburg, MD, USA, ${ }^{2}$ Research and Development, Translabion, Clarksburg, MD, USA, ${ }^{3}$ Department of Chemistry, Rutgers University, Newark, NJ, USA, ${ }^{4}$ Building Environment Division, National Institute of Standards and Technology (NIST), Gaithersburg, MD, USA, ${ }^{5}$ Sibley School of Mechanical and Aerospace Engineering, Cornell University, Ithaca, NY, USA, ${ }^{6}$ Department of Chemistry and Environmental Science, New Jersey Institute of Technology, Newark, NJ, USA and ${ }^{7}$ Division of Cancer Prevention, National Cancer Institute (NCI), Bethesda, MD, USA

Email: Yan Xiao* - yan.xiao@nist.gov; Xiugong Gao - xiugong.gao@translabion.com; Oleh Taratula - olehtaratula@gmail.com; Stephen Treado - stephen.treado@nist.gov; Aaron Urbas - aaron.urbas@nist.gov; R David Holbrook - dave.holbrook@nist.gov; Richard E Cavicchi - richard.cavicchi@nist.gov; C Thomas Avedisian - cta2@cornell.edu; Somenath Mitra - somenath.mitra@njit.edu; Ronak Savla - rsavla@eden.rutgers.edu; Paul D Wagner - wagnerp@mail.nih.gov; Sudhir Srivastava - srivasts@mail.nih.gov; Huixin He* - huixinhe@newark.rutgers.edu

* Corresponding authors †Equal contributors
\end{abstract}

Published: 2 October 2009

BMC Cancer 2009, 9:35। doi:|0.||86/|47|-2407-9-35|
Received: 16 December 2008

Accepted: 2 October 2009

This article is available from: http://www.biomedcentral.com/I47I-2407/9/35 I

(c) 2009 Xiao et al; licensee BioMed Central Ltd.

This is an Open Access article distributed under the terms of the Creative Commons Attribution License (http://creativecommons.org/licenses/by/2.0), which permits unrestricted use, distribution, and reproduction in any medium, provided the original work is properly cited.

\begin{abstract}
Background: Nanocarrier-based antibody targeting is a promising modality in therapeutic and diagnostic oncology. Single-walled carbon nanotubes (SWNTs) exhibit two unique optical properties that can be exploited for these applications, strong Raman signal for cancer cell detection and near-infrared (NIR) absorbance for selective photothermal ablation of tumors. In the present study, we constructed a HER2 IgY-SWNT complex and demonstrated its dual functionality for both detection and selective destruction of cancer cells in an in vitro model consisting of HER2expressing SK-BR-3 cells and HER2-negative MCF-7 cells.
\end{abstract}

Methods: The complex was constructed by covalently conjugating carboxylated SWNTs with anti-HER2 chicken IgY antibody, which is more specific and sensitive than mammalian IgGs. Raman signals were recorded on Raman spectrometers with a laser excitation at $785 \mathrm{~nm}$. NIR irradiation was performed using a diode laser system, and cells with or without nanotube treatment were irradiated by $808 \mathrm{~nm}$ laser at $5 \mathrm{~W} / \mathrm{cm}^{2}$ for $2 \mathrm{~min}$. Cell viability was examined by the calcein AM/ ethidium homodimer-I (EthD-I) staining.

Results: Using a Raman optical microscope, we found the Raman signal collected at single-cell level from the complex-treated SK-BR-3 cells was significantly greater than that from various control cells. NIR irradiation selectively destroyed the complex-targeted breast cancer cells without harming receptor-free cells. The cell death was effectuated without the need of internalization of SWNTs by the cancer cells, a finding that has not been reported previously. 
Conclusion: We have demonstrated that the HER2 IgY-SWNT complex specifically targeted HER2-expressing SK-BR-3 cells but not receptor-negative MCF-7 cells. The complex can be potentially used for both detection and selective photothermal ablation of receptor-positive breast cancer cells without the need of internalization by the cells. Thus, the unique intrinsic properties of SWNTs combined with high specificity and sensitivity of IgY antibodies can lead to new strategies for cancer detection and therapy.

\section{Background}

Although significant progress has been made in both the understanding and treatment of cancer during the last thirty years, it remains the second leading cause of death in the United States. Non-invasive detection of cancer in its early stages is of great interest since early cancer diagnosis, in combination with precise cancer therapies, could significantly increase the survival rate of patients. Nanomedicine, an emerging research area that integrates nanomaterials and biomedicine, has the potential to provide novel diagnostic tools for detection of primary cancers at their earliest stages, and to provide improved therapeutic protocols. Research in nanomedicine will also lead to the understanding of the intricate interplay of nanomaterials with components of biological systems.

Attaching antibodies or other targeting agents (such as receptor ligands) to the surface of nanocarriers to achieve specific targeting of cancerous cells is a promising modality for therapeutic and diagnostic oncology [1]. Improved therapeutic efficacy of targeted nanocarriers has been established in multiple animal models of cancer, and currently more than 120 clinical trials are underway with various antibody-containing nanocarrier formulations [2]. The most commonly explored nanocarriers include polymer conjugates, polymeric nanoparticles, lipid-based carriers such as liposomes and micelles, and dendrimers [1]. Recent developments in nanotechnology have engendered a range of novel inorganic nanomaterials, such as metal nanoshells [3] and carbon nanotubes [4], offering unique opto-electronic properties compared with conventional organic nanocarriers $[3,4]$.

Single-walled carbon nanotube (SWNT) is a novel nanomaterial that exhibits unique structural, mechanical, electrical and optical properties that are promising for various biological and biomedical applications, such as biosensors [5], novel biomaterials [6], and drug delivery transporters [7-11]. Water-solubilized SWNTs have been shown to transverse the cell membrane via endocytosis to shuttle various cargoes into cells, including proteins [12], nucleic acid such as plasmid DNA $[13,14]$ and short interfering RNA [15], without causing cytotoxicity. Two unique intrinsic properties of SWNTs can be exploited to facilitate cancer detection and therapy. SWNTs have very strong resonant Raman scattering [16] that can be harnessed for cancer cell detection [17-19]. SWNTs absorb NIR light in the 700-1100 nm spectral window to which biological systems are transparent; continuous NIR irradiation of SWNTs attached to cancer cells produces excessive heat in the local environment that can be utilized to achieve selective destruction of these cells without harming normal cells [7,20-22].

To achieve specific targeting of tumor cells for photothermal ablation, SWNTs have been either conjugated to folate to target folate receptors in folate positive cancer cells $[7,22]$ or attached noncovalently (through adsorption) [20] or indirectly via streptavidin-biotin interaction [21] to antibodies targeting specific receptors on cancer cells. Direct covalent attachment of antibodies to SWNTs for specific tumor targeting has also been reported [23], however, using such antibody-SWNT conjugates for specific photothermal ablation of cancer cells with NIR light has not been reported.

All of the antibodies in clinical use today for cancer cell targeting are mammalian IgG monoclonal antibodies [24]. Recently, there has been renewed interest in using avian IgY antibodies as IgG substitutes in immunoassays and clinical applications [25]. IgYs, distinct from IgGs in molecular structure and biochemical features, have many attractive biochemical, immunological and production advantages over IgGs and are suitable for further development [25]. We have recently demonstrated the advantages of using anti-HER2 IgY antibody in detecting breast cancer cells [26]. IgY antibodies provide specific and more sensitive detection of breast cancer cells compared with commercial IgG or IgM antibodies. Coupled with quantum dots, anti-HER2 IgY antibodies have the potential to give quantitative biomarker measurements [26].

In an effort to improve breast cancer detection and therapy, we have developed a novel method which combines the advantages of anti-HER2 IgY antibody with the unique properties of SWNTs. We constructed a HER2 IgY-SWNT complex by directly functionalizing SWNTs with the antiHER2 IgY antibody through covalent bonding, explored the Raman and NIR optical properties of the complex, and tested its feasibility for detection and selective destruction of cancer cells. 


\section{Methods \\ Preparation of the HER2 IgY-SWNT complex}

Purified HiPco SWNTs were purchased from Carbon Nanotechnologies (Houston, TX) and solubilized by carboxylation using a microwave-assisted functionalization method described previously [27]. In a typical reaction, $\sim 1 \mathrm{mg}$ of as-received carbon nanotubes were added into 2 $\mathrm{ml}$ of a $1: 1$ mixture of $70 \%$ nitric acid and $97 \%$ sulfuric acid aqueous solutions in a plastic beaker. The mixture was then subjected to microwave radiation for $2 \mathrm{~min}$. Afterwards, the mixture was diluted with deionized water and centrifuged at $2000 \mathrm{~g}$ for $15 \mathrm{~min}$ to remove insoluble materials. The supernatant was filtered through a Microcon YM-50 centrifugal filter unit (Millipore, Billerica, MA) and rinsed thoroughly with $100 \mathrm{mM}$ MES buffer in order to adjust $\mathrm{pH}$ to 4.5 . For covalent attachment of HER2 IgY antibody onto SWNTs, $2.0 \mathrm{mg}$ N-(3-Dimethylaminopropyl)-N'-ethylcarbodiimide hydrochloride (EDC), $88.3 \mathrm{mg}$ N-Hydroxysuccinimide (NHS) and $100 \mu \mathrm{L}$ MES buffer solution ( $100 \mathrm{mM}, \mathrm{pH} 4.5$ ) were added to the microwavefunctionalized SWNT solution and incubated for $60 \mathrm{~min}$ at room temperature. The mixture was then centrifuged in Microcon YM-50 centrifugal filter unit and rinsed with a $100 \mathrm{mM}$ MES buffer solution ( $\mathrm{pH}$ 6.3) to remove excess EDC, NHS and the byproduct urea. The purified, activated carbon nanotubes on the filter were re-dispersed into a $100 \mathrm{mM}$ MES buffer solution ( $\mathrm{pH}$ 6.3). Thereafter, $60 \mu \mathrm{l}$ $(1.0 \mathrm{mg} / \mathrm{ml})$ chicken anti-HER2 IgY antibody, prepared as described previously [26], was added into the above solution and reacted for $2 \mathrm{~h}$. Finally, the solution was centrifuged at $25,000 \mathrm{~g}$ for $20 \mathrm{~min}$ to remove the unreacted materials. The collected precipitate was resuspended in PBS buffer (100 mM, pH 7.4) and used for further studies. The concentration of antibody conjugated to SWNTs was determined using BCA protein assay (Pierce, Rockford, IL) following the manufacturer's instructions. The SWNT concentration in the solution was estimated from the absorbance spectrum at $808 \mathrm{~nm}$ acquired with a Cary-500 UVvisible-NIR spectrophotometer (Varian, Palo Alto, CA) in double-beam mode.

\section{Cell culture and treatment}

Breast carcinoma cell lines SK-BR-3 and MCF-7 were obtained from ATCC (Manassas, VA) and cultured under conditions as recommended by the supplier. Cells were grown for 24 h to reach $\sim 30-40 \%$ confluence, then treated with the HER2 IgY-SWNT complex or SWNT or antibody alone at the final nanotube concentration of $4 \mathrm{mg} / \mathrm{L}$ for 24 $\mathrm{h}$ under the same culture condition. The cell culture was washed 3 times with fresh medium before NIR irradiation to remove unbound nanotubes, antibodies or the antibody nanotube complex.

\section{Atomic force microscopy (AFM)}

The SWNTs before and after conjugation with anti-HER2 IgY antibody were imaged with a tapping mode Nano- scope IIIa atomic force microscope (Veeco, Chadds Ford, PA). In order to image the SWNTs, $5 \mu$ l of the prepared solutions were deposited on freshly cleaved mica. After a 3-5 min incubation, the mica surface was rinsed with 3 drops of deionized water 4 times and dried under a flow of nitrogen. During imaging, a $125 \mu \mathrm{m}$ long rectangular silicon cantilever/tip assembly was used with a spring constant of $40 \mathrm{~N} / \mathrm{m}$, resonance frequency of $315-352 \mathrm{kHz}$ and a tip radius of $5-10 \mathrm{~nm}$. The images were generated by the change in amplitude of the free oscillation of the cantilever as it interacts with the sample.

\section{Dispersive Raman spectrometric analysis}

Raman spectra for the HER2 IgY-SWNT complex solution were collected on a S1000 Raman spectrometer from Renishaw (Hoffman Estates, IL) coupled to a DM LM microscope from Leica (Bannockburn, IL) using a 50× objective. The source was an Ar-ion pumped tunable Ti:sapphire laser from Coherent (Santa Clara, CA) operating at 785 $\mathrm{nm}$. Laser power was $7 \mathrm{~mW}$ measured at the sample.

Senterra dispersive Raman spectrometer from Bruker Optics (Billerica, MA) was used to collect Raman spectra from cell cultures. The system consisted of laser excitation at $785 \mathrm{~nm}$ focused on the samples through an optical system, producing spectra of Raman shifts, which were evaluated to identify and determine the presence and location of the nanomaterial. Measurements were made using a $10 \times$ objective lens, with laser powers ranging from 1 to 25 $\mathrm{mW}$, and exposure times of 10 to $60 \mathrm{~s}$. Various settings were tried in order to determine the optimum signal-tonoise ratio and to avoid damaging the samples from overheating by the laser.

\section{NIR irradiation and temperature measurement}

A Spectra-Physics diode laser from Newport (Irvine, CA) at a wavelength of $808 \mathrm{~nm}$ mounted on a heat sink was employed to heat the samples. The heat sink was controlled by a driver and a temperature controller. Two thermocouples made from $80 \mu \mathrm{m}$ diameter type $\mathrm{K}$ wire from Omega (Stamford, CT) were positioned outside of the beam path to record the temperature response. A program written in LabVIEW (National Instruments, Austin, TX) was used to control the timing and power of the laser and to record the temperature of the two thermocouple junctions. The laser exposure was conducted at a current of 3.0 $A$ in the laser diode which produced an output of $5 \mathrm{~W} /$ $\mathrm{cm}^{2}$, and the duration was set to $120 \mathrm{~s}$.

Samples were contained in cells with a $1 \mathrm{~cm} \times 1 \mathrm{~cm}$ glass bottom. A removable Teflon cap was fitted over the cells. A $4.5 \mathrm{~mm}$ hole was drilled through the cap for the laser to pass through (the beam diameter was $4.4 \mathrm{~mm}$ ). Two smaller holes were drilled through the cap for the thermocouple wires to pass through. One of the thermocouples was extended below the cap into the fluid and positioned 
just at the edge of the illuminated area. The second was positioned approximately $1 \mathrm{~mm}$ outside the edge of the beam path. The beam passed through the sample's glass bottom and entered a $3 \mathrm{~cm}$ diameter beam dump located just below the glass bottom. The beam dump serves to prevent radiation passing through the sample from making its way back to the sample. A diagram for the laser exposure arrangement is shown in Fig. 1.

\section{Cell viability assay}

Ten (10) min after heating with NIR irradiation, cell viability was examined by the calcein AM/ethidium homodimer-1 (EthD-1) staining [28]. The LIVE/DEAD Viability/Cytotoxicity Kit from Molecular Probes (Eugene, OR) was used and protocols provided by the manufacturer were adopted. Cells showing green fluorescence were considered alive; while dead cells showed red fluorescence. Results were expressed as percentage of live cells relative to the number of cells on a control slide that did not go through treatment or NIR irradiation.

SWNTs localization study by immunohistochemistry (IHC) Cells were grown on tissue culture chamber slides (Nunc, Rochester, NY) at a density of 30,000 cells $/ \mathrm{cm}^{2}$ and then treated with the HER2 IgY-SWNT complex at the final nanotube concentration of $4 \mathrm{mg} / \mathrm{L}$ for $24 \mathrm{~h}$. Cell monolayers were subsequently fixed in 10\% neutral-buffered zinc formalin (Fisher, Pittsburgh, PA), and were preblocked with $5 \%(\mathrm{w} / \mathrm{v})$ nonfat dry milk in TBST $(50 \mathrm{mM}$ Tris-HCl, $150 \mathrm{mM} \mathrm{NaCl}, 150 \mathrm{mM}$ Tween 20), $20^{\circ} \mathrm{C}$, for $20 \mathrm{~min}$. For detection, slides were robotically prepared

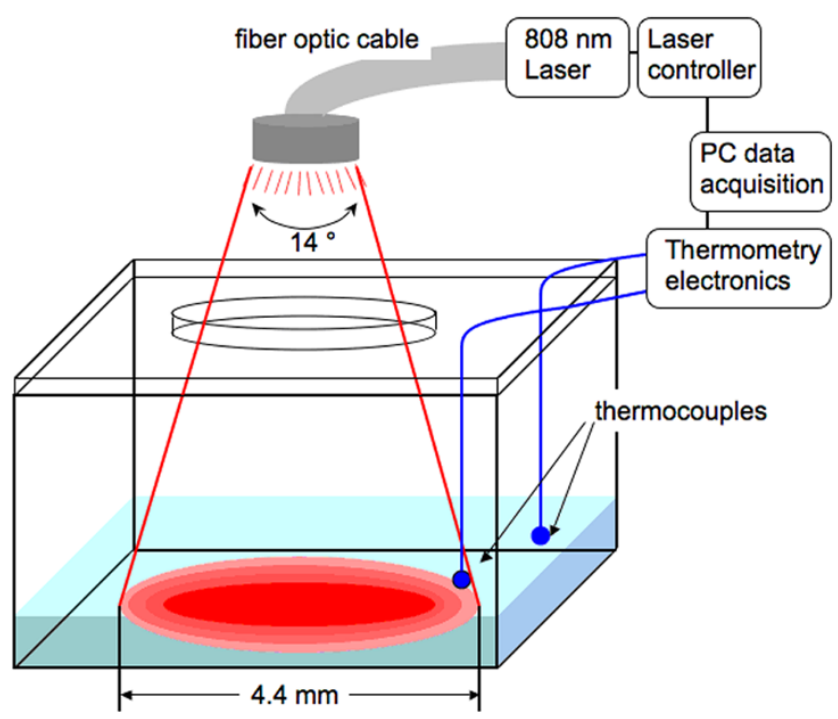

Figure I

Schematic of experimental setup for NIR irradiation and temperature measurement. Dimensions not to scale. (reaction with secondary antibody and fluorescent detection reagents) with a Benchmark XT workstation (Ventana, Tucson, AZ) [29]. Anti-IgY biotinylated antibody (GenWay, San Diego, CA) was used as the secondary antibody and was detected by fluorescence microscopy with streptavidin-Qdot655 (Invitrogen, Carlsbad, CA). Imaging systems for analysis of fluorescence signals from quantum dots and integration of the signal with an imaging system were described elsewhere [30,31].

Confocal laser scanning microscopy images were obtained on a TCS SP5/DM6000 from Leica using an HCX Pl Apo oil immersion $63 \times$ coverslip corrected objective. A $405 \mathrm{~nm}$ Diode laser was used as the excitation source while the emission bands were set to $440 \mathrm{~nm}$ to $480 \mathrm{~nm}$ (DAPI, channel 1), $640 \mathrm{~nm}$ to $660 \mathrm{~nm}$ (QDs, channel 2), and diffraction (cells, channel 3). Zoom functions between $1 \times$ and $6 \times$ were used as needed.

\section{Data analysis}

All experiments were repeated at least 3 times with at least 3 replicates each time. For comparative studies, one-way ANOVA tests (with Bonferroni post test if $p<0.05$ ) were used for statistical analysis. Differences were considered statistically significant if a $p$ value of $<0.05$ was achieved.

\section{Results \\ Preparation and characterization of the HER2 IgY-SWNT Complex}

The HER2 IgY-SWNT complex was prepared by first carboxylating HiPco SWNTs using a microwave-assisted functionalization method published previously [27]; the carboxylated SWNTs were then activated by N-(3-Dimethylaminopropyl)-N'-ethylcarbodiimide hydrochloride (EDC) and N-Hydroxysuccinimide (NHS) and reacted with HER2 IgY antibody to form the covalent complex, through amidation between the carboxyl groups on the SWNTs with primary amines on amino acid residues such as lysine and arginine on the antibody (Fig. 2A) [32]. Free unconjugated antibodies were removed through ultracentrifugation. The SWNTs used consisted of short, straight fragments (with average diameter and length being $1.17 \pm$ $0.28 \mathrm{~nm}$ and $88.00 \pm 43.68 \mathrm{~nm}$, respectively) and exist as individual tubes and small bundles rather than large aggregates as evidenced by atomic force microscopy (AFM) image (Figs. 2B and 2C). After antibody attachment, the diameter of the nanotubes increased to $4.02 \pm$ $0.82 \mathrm{~nm}$ (Figs. 2D and 2E). Based on the concentrations of the carbon nanotubes and the IgY antibodies used, it was estimated that on average about $10 \mathrm{IgY}$ antibody molecules were attached to each nanotube. The nanotube complex solutions were highly stable in PBS buffer, without forming aggregates for several months when kept at $4^{\circ} \mathrm{C}$. 


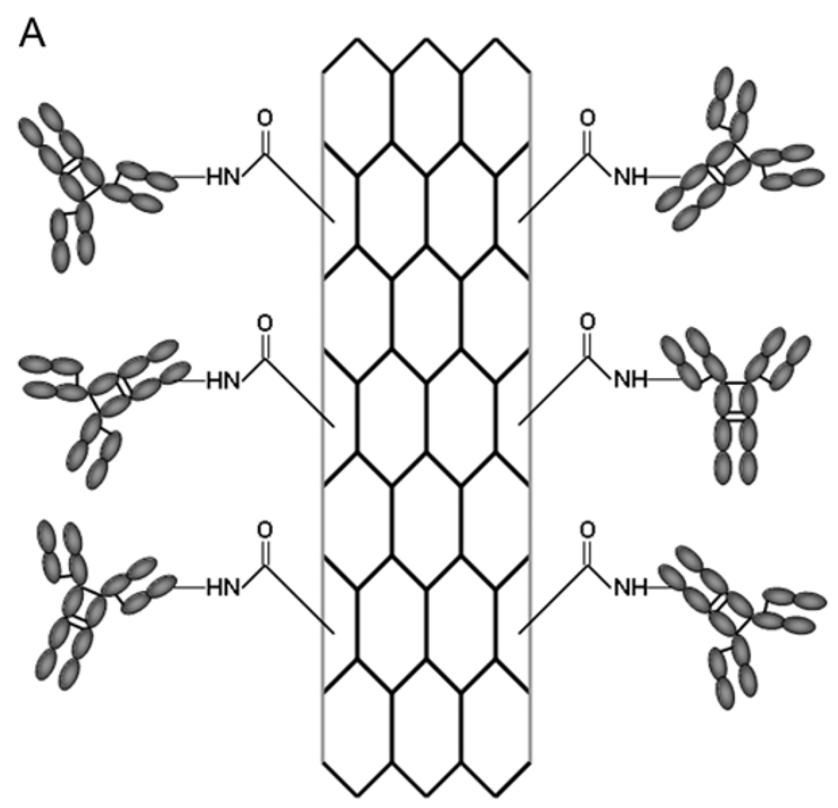

A
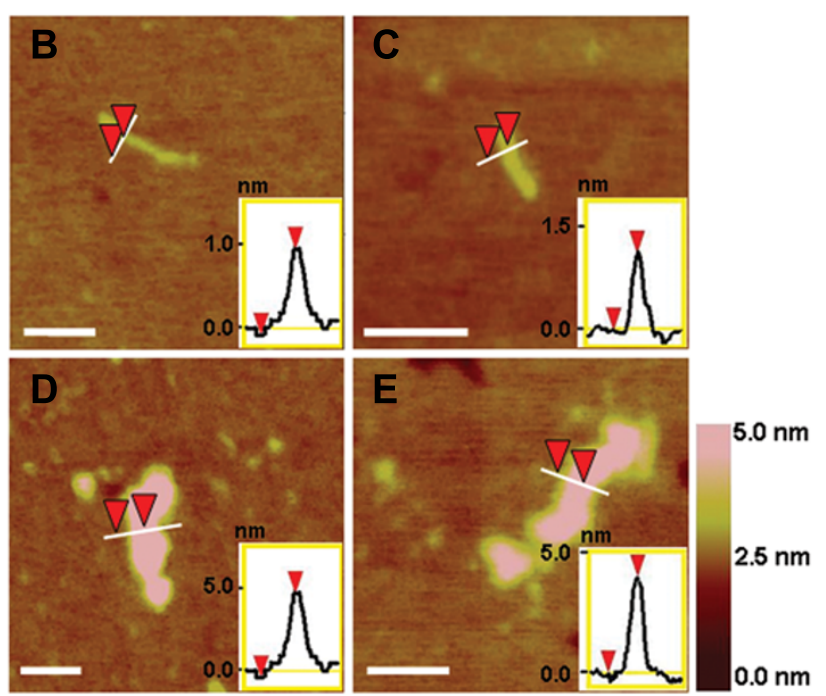

\section{Figure 2}

The HER2 IgY-SWNT complex. (A) Schematic representation of SWNTs covalently functionalized with antiHER2 IgY antibody. (B-E) atomic force microscopy (AFM) images of carboxylated SWNTs prior to conjugation ( $B$ and $C)$ and after conjugation (D and E) to anti-HER2 IgY antibodies. Insets shows AFM cross-section analysis indicating the changes in height of SWNTs prior to and after conjugation with anti-HER2 IgY antibodies. The height differences on the surface are indicated by the color code shown on the right. Scale bars represent $60 \mathrm{~nm}$.

The optical properties of the freshly prepared HER2 IgYSWNT complex were tested. The Raman spectra (Fig. 3A) of the complex showed a number of well characterized resonances such as the radial breathing mode (RBM) region between 100 and $300 \mathrm{~cm}^{-1}$ and the tangential (G-

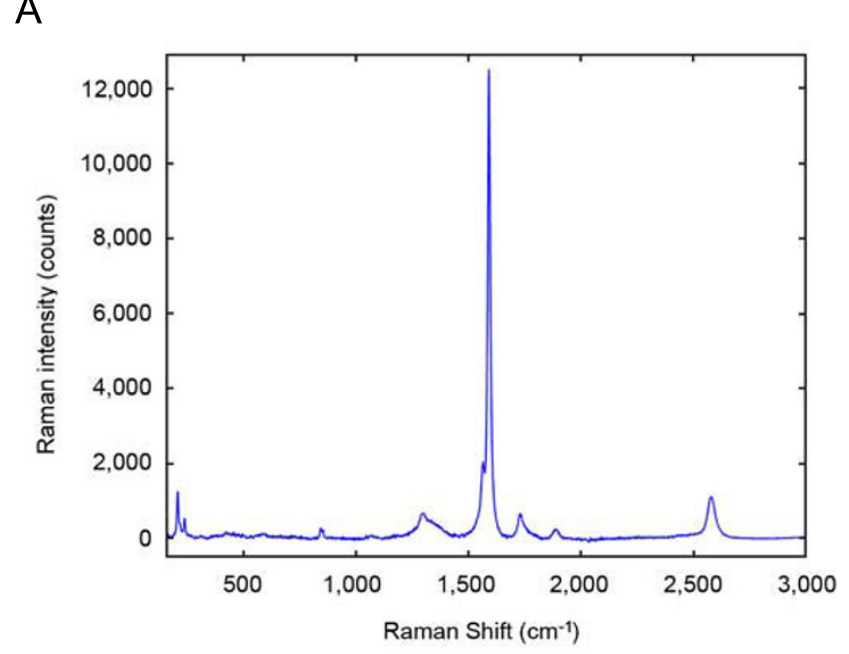

B

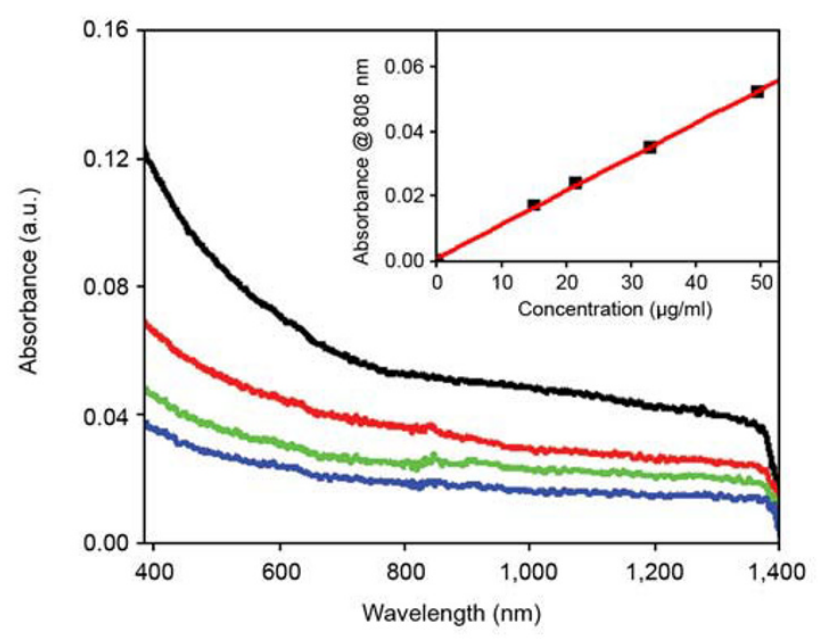

Figure 3

Optical properties of the HER2 IgY-SWNT complex. (A) Raman spectra. (B) UV-visible-NIR spectra at different nanotube concentrations (from top to bottom: 49.70, 33.02, $21.6 \mathrm{I}$ and $15.1 \mathrm{I} \mu \mathrm{g} / \mathrm{ml}$ ). Inset shows the linear relationship of the absorption at $808 \mathrm{~nm}$ versus concentration (optical path $=0.3 \mathrm{~cm}$ ).

band) peak at $1,590 \mathrm{~cm}^{-1}$. A narrow $\mathrm{G}$ - feature was also visible in the G-band region, confirming the presence of semiconducting SWNTs in the sample. The spectra also contained the disorder-induced D band around $1300 \mathrm{~cm}^{-}$ 1. The UV-visible-NIR spectra (Fig. 3B) indicated that the HER2 IgY-SWNT complex has fairly strong absorbance in the NIR region (700-1100 nm spectral window), even though the interband absorption peaks, originating from electronic transitions between the first and second van Hove singularities of the nanotubes $[33,34]$ were smeared out during the microwave dispersing and IgY functionalization process. Thus, SWNTs covalently functionalized 
with antibody retained a significant portion of their optic properties that are potentially useful for biomedical applications.

\section{Raman spectrometric detection of cancer cells using the HER2 IgY-SWNT complex}

We first explored the feasibility of harnessing the characteristic $1590 \mathrm{~cm}^{-1}$ Raman band for in vitro specific detection of cancer cells. Breast carcinoma SK-BR-3 cells, which have high HER2 expression [26], were treated with the HER2 IgY-SWNT complex for $24 \mathrm{~h}$. Raman spectroscopy collected at single-cell level from randomly selected cells showed the characteristic G band at $\sim 1590 \mathrm{~cm}^{-1}$ (Fig. 4). The Raman signal from the complex-treated breast cancer cells resulted from the specific binding of the IgY antibody moiety of the complex to the HER2 receptor on the cancer cells, as the same cells treated with SWNTs alone did not exhibit Raman scattering. In addition, MCF-7, which are negative for HER2 expression [26], did not exhibit Raman signals when treated with the HER2 IgY-SWNT complex. Thus the characteristic Raman band at $\sim 1590 \mathrm{~cm}^{-1}$ from the HER2 IgY-SWNT complex differentiated HER2expressing SK-BR-3 cells from the receptor-negative MCF7 cells.

\section{NIR irradiation-induced heating of the HER2 IgY-SWNT complex suspension}

To demonstrate the heating effect of the HER2 IgY-SWNT complex upon NIR irradiation, we carried out a control

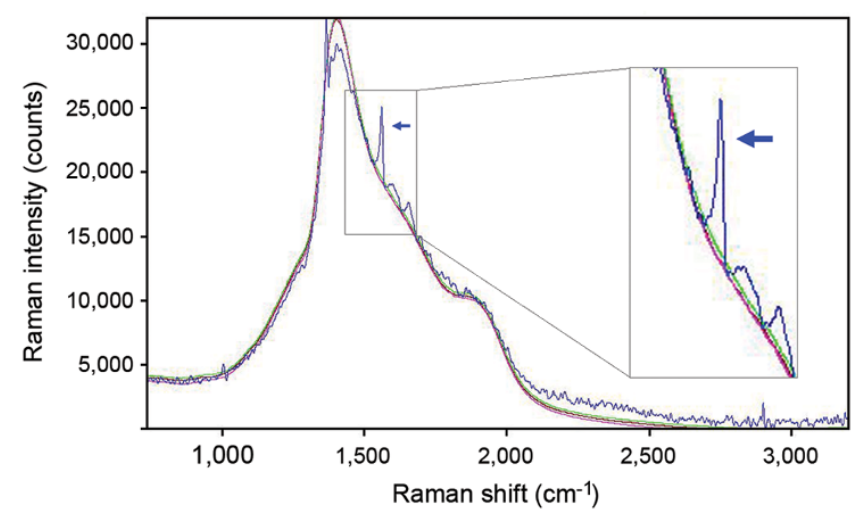

\section{Figure 4}

Raman spectra of breast cancer cells treated by the HER2 IgY-SWNT complex. A $785 \mathrm{~nm}$ laser diode was used for excitation at I-25 mW through a $10 \times$ objective lens on randomly selected cells. Raman spectra of a representative cell from each sample are shown. Blue line, SK-BR-3 cell treated with the HER2 IgY-SWNT complex; red line, SK-BR3 cell treated with SWNT alone; magenta line, untreated SKBR-3 cell; green line, MCF-7 cell treated with the HER2 lgYSWNT complex. The Raman signal indicated by the arrow is the characteristic $G$ band at $\sim 1590 \mathrm{~cm}^{-1}$. Inset shows higher resolution spectrum in the area around $1590 \mathrm{~cm}^{-1}$. experiment in which an aqueous solution of the HER2 IgY-SWNT complex in PBS at a concentration of $4.0 \mathrm{mg} / \mathrm{L}$ was irradiated for 2 min using a laser diode with a wavelength of $808 \mathrm{~nm}$ at $5.0 \mathrm{~W} / \mathrm{cm}^{2}$ (Fig. 5). The temperature rose rapidly after a short lag of a few seconds then increased constantly with time. The maximum temperature increase was $\sim 14^{\circ} \mathrm{C}$. On the other hand, PBS solution without SWNTs showed very little temperature rise $\left(<1^{\circ} \mathrm{C}\right)$, indicating the solution is transparent to the 808 nm NIR light.

\section{Selective photothermal ablation of cancer cells using the HER2 IgY-SWNT complex}

Next, we explored the feasibility of using the HER2 IgYSWNT complex for in vitro selective destruction of breast carcinoma SK-BR-3 cells (Fig. 6). We conducted the NIR irradiation with a $808 \mathrm{~nm}$ laser at $5 \mathrm{~W} / \mathrm{cm}^{2}$ for $2 \mathrm{~min}$. SKBR-3 cells treated with the HER2 IgY-SWNT complex showed extensive cell death after heating with NIR irradiation (Figs. 6D and 6G); in stark contrast, negligible cell death was observed with SK-BR-3 cells treated with SWNTs alone (Figs. 6B and 6G) or untreated (Figs. 6A and $6 \mathrm{G})$, and in MCF-7 cells treated with the HER2 IgY-SWNT complex (Fig. 6F). These results clearly demonstrated the high transparency of biosystems to NIR light in the vicinity of $808 \mathrm{~nm}$, and at the same time indicated that the specific binding of the IgY antibody moiety of the complex with HER2 receptors on the SK-BR-3 cells is essential for the selective thermal ablation of tumor cells. On the other hand, the SWNT moiety is equally indispensable for the hyperthermia effect, as cell death observed in SK-BR-3 cells treated with the IgY antibody alone (5.9\%; Figs. 6C

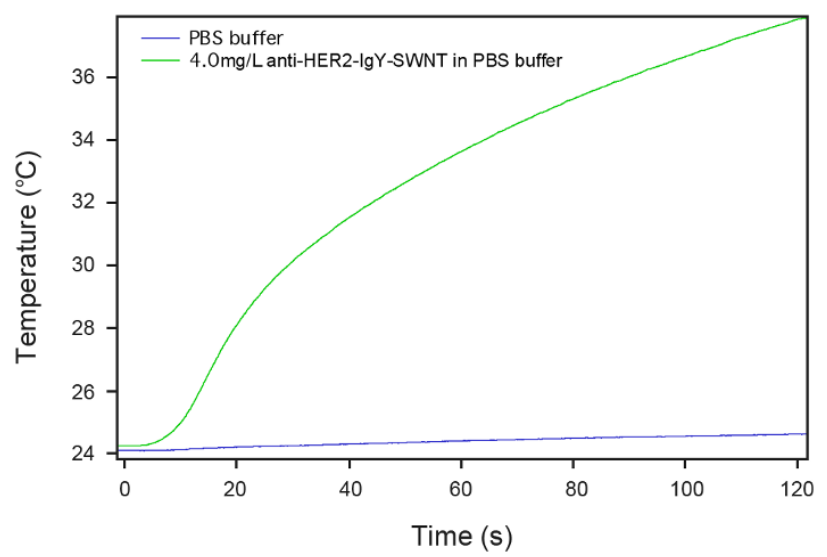

Figure 5

Temperature measurement during NIR irradiation. The green line records the temperature evolution of the HER2 IgY-SWNT complex solution at a concentration of 4 $\mathrm{mg} / \mathrm{L}$ during continuous irradiation by a $808-\mathrm{nm}$ laser at 5.0 $\mathrm{W} / \mathrm{cm}^{2}$ for $2 \mathrm{~min}$. The blue line records that for the phosphate-buffered saline (PBS) solution. 

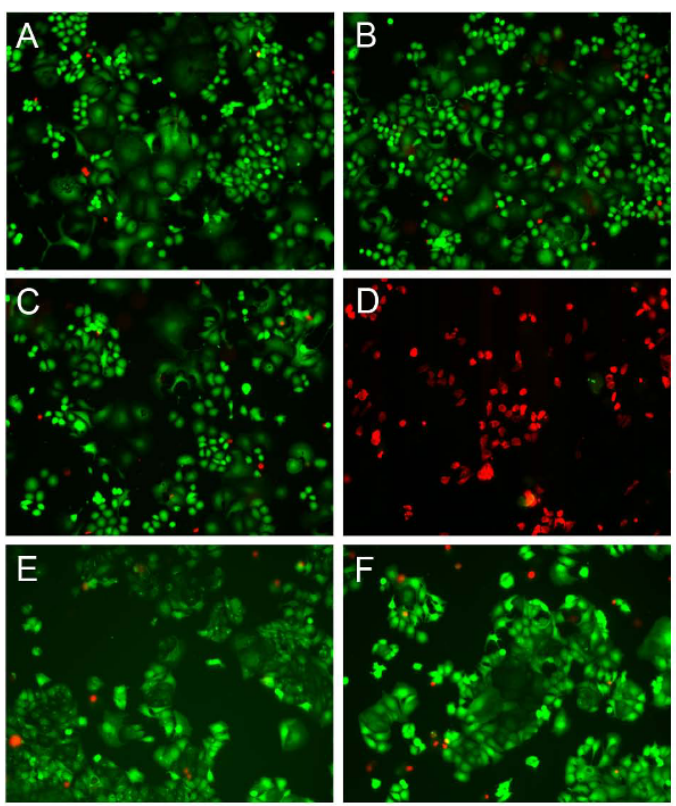

G

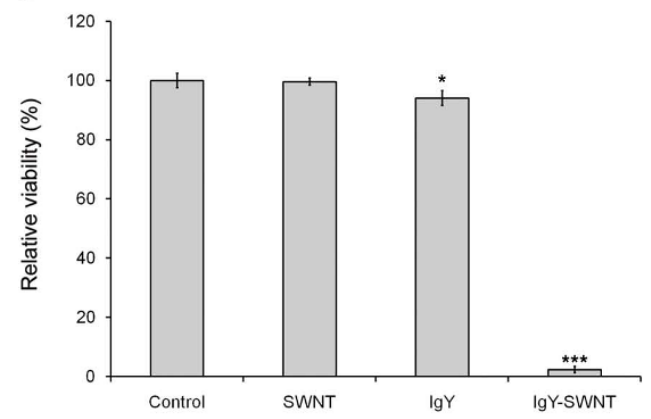

Figure 6

Cell viability after treatment with the HER2 IgYSWNT complex followed by NIR irradiation. Cell viability was examined by calcein AM/EthD-I fluorescence staining and representative images from each sample are shown. Cells with green fluorescence were considered alive, whereas those with red fluorescence were dead. $(A)$ Untreated SK-BR-3 cells. (B) SK-BR-3 cells treated with SWNT alone. (C) SK-BR-3 cells treated with anti-HER2 IgY antibody alone. (D) SK-BR-3 cells treated with the HER2 IgYSWNT complex. (E) Untreated MCF-7 cells. (F) MCF-7 cells treated with the HER2 IgY-SWNT complex. All treatments were for $24 \mathrm{~h}$, followed by NIR irradiation with a $808 \mathrm{~nm}$ laser at $5 \mathrm{~W} / \mathrm{cm}^{2}$ for $2 \mathrm{~min}$. Magnification for all the images (A-F) was I0×. (G) Bar graph showing the percentage of live cells in each sample of SK-BR-3 cells following NIR irradiation. Cells were counted under microscope for 3 randomly selected view fields, and the total number was used for the calculation. The experiment was repeated for 3 times $(n=3)$. Error bars represent standard deviation. Cells that did not go through treatment and irradiation were used as controls $(852 \pm 20,100 \%)$. $* p<0.05$ and $* * * p<0.001$ versus control.

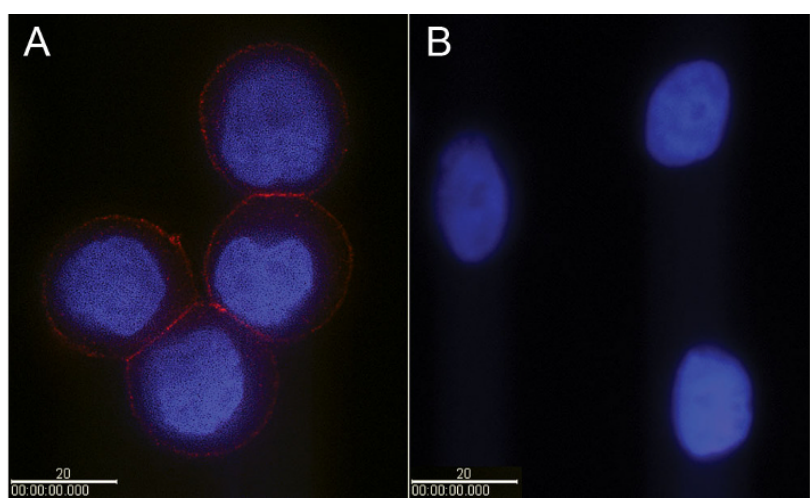

Figure 7

Localization of the HER2 IgY-SWNT complex on the cell membrane. (A) SK-BR-3 cells. (B) MCF-7 cells. The HER2 IgY antibody on the complex was probed by biotinylated anti-lgY antibody and detected by fluorescence microscopy with streptavidin-Qdot655 fluorophores. Bars represent $20 \mu \mathrm{m}$.

and 6G), although statistically significant $(p=0.040)$, was to a much less extent than in cells treated with the complex $\left(97.7 \%, p=3.38 \times 10^{-7}\right.$; Figs. 6D and 6G).

\section{Localization of the HER2 IgY-SWNT complex on the cell membrane}

To localize the HER2 IgY-SWNT complexes in the cancer cells, we first performed an immunohistochemical experiment using quantum dots as detection agent. As shown in Fig. 7A, most of the HER2 IgY-SWNT complexes were localized on the membrane of the SK-BR-3 cells forming a shell-like shape, with little detected inside the cells. Fluorescence signal computed from 10 randomly selected cells shows that the intensity ratio of fluorescence on the cell surface to that inside the cell is $(563 \pm 35)$ : 1 . No fluorescence signal was detected in receptor-free MCF-7 cells (Fig. $7 \mathrm{~B})$, suggesting that binding of the complex onto SK-BR-3 cells resulted from the anti-HER2 activity of its antibody moiety.

To confirm the above result, we performed additional experiments using confocal microscopy for imaging. The high-resolution images shown in Fig. 8 clearly demonstrated that the HER2 IgY-SWNT complexes were localized on the membrane of the SK-BR-3 cells and were not internalized by the cancer cells.

\section{Discussion}

The first problem to tackle for biomedical applications of SWNTs is to solubilize and disperse carbon nanotubes in aqueous solutions and functionalize them with biomolecules such as proteins/antibodies, nucleic acids and carbohydrates. Past studies using SWNT-antibody conjugates for specific photothermal ablation of cancer cells attached 
antibodies to SWNTs either noncovalently through adsorption [20] or indirectly via streptavidin-biotin interaction [21]. Direct adsorption of antibodies to SWNTs is simple to execute but the weak interaction between the antibody and the nanotubes raises the possibility of loss of the targeting function of the antibodies. Indirect conjugation via streptavidin-biotin interaction involves an additional step of preparing the antibody-biotin complex. A method for direct covalent attachment of antibodies to SWNTs for specific tumor targeting has been reported [23] that involves four reactive steps. Here, we used a simpler method for direct covalent conjugation of antibody to SWNTs. HiPco SWNTs were first dispersed in water through microwave-assisted carboxylation, activated by EDC and NHS, and reacted with HER2 IgY antibody to form the covalent complex. Microwave-assisted functionalization has several advantages over conventional chemical techniques, such as rapidness and environmental friendliness [27]. However, the functionalization process causes some changes in the optoelectronic properties of the SWNTs, such as increase in the disorder mode (Dband) at $\sim 1300 \mathrm{~cm}^{-1}$ (Fig. 3A) and loss of interband transitions between van Hove singularities in the absorption spectrum (Fig. 3B). Similar changes have been reported previously for covalently functionalized carbon nanotubes $[27,35,36]$. Nevertheless, the resultant IgY-SWNT complexes retain a significant portion of the optic properties of SWNTs, as evidenced by the fairly strong Raman and NIR absorbance.

The characteristic G band at $\sim 1590 \mathrm{~cm}^{-1}$ was detected in HER2-expressing SK-BR-3 cells treated with the IgY-SWNT complexes (Fig. 4) but not in the similarly treated receptor-negative MCF-7 cells, indicating the ability of Raman spectroscopy to specifically detect cancer cells in vitro. As a nondestructive optical spectroscopic technique that does not require extrinsic contrast-enhancing agents, the use of
Raman spectroscopy has seen a remarkable increase during the last decade in its application to the field of medicine [37]. In particular, Raman spectroscopy has shown great promise as a new tool for detection of malignant and premalignant tissues and as a real-time guidance tool during oncosurgical procedures [38]. However, most of these studies are based on spectral differences between normal and neoplastic tissues that result from compositional changes in the affected tissues, and thus, in most cases, the detection is not highly specific and only possible at later stages of tumor progression. In the current study, characteristic Raman signals (at $\sim 1590 \mathrm{~cm}^{-1}$ ) are collected at the single-cell level from cancer cells targeted by the IgYSWNT complexes, thus opening the possibility of using Raman spectroscopy for targeted molecular detection of tumors at the incipient stage. An added advantage of Raman spectroscopy lies in its potential for in vivo applications for which limited penetration depth is a fundamental barrier. Until recently, Raman spectroscopy has been generally restricted to probing surface or near-surface areas of biological tissues with penetration depth of only several hundred microns into tissue. This limitation mainly stems from the diffuse scattering nature of tissue which leads to random propagation of photons within its matrix and prevents the formation of sharp images required to discriminate signals emerging from deeper areas. Several methods have been developed recently for the retrieval of Raman signals from deep areas thus enhancing tissue penetration of Raman spectroscopy. These deep Raman techniques discriminate between Raman signals emerging from different depths within the sample using temporal or spatial gating [39]. For instance, combining spatially offset Raman spectroscopy (SORS) with three-dimensional tomographic imaging, it was possible to image a canine hind limb section of a thickness of up to $45 \mathrm{~mm}$ using transmission Raman spectroscopy $[40,41]$. Therefore, combined with advances in Raman
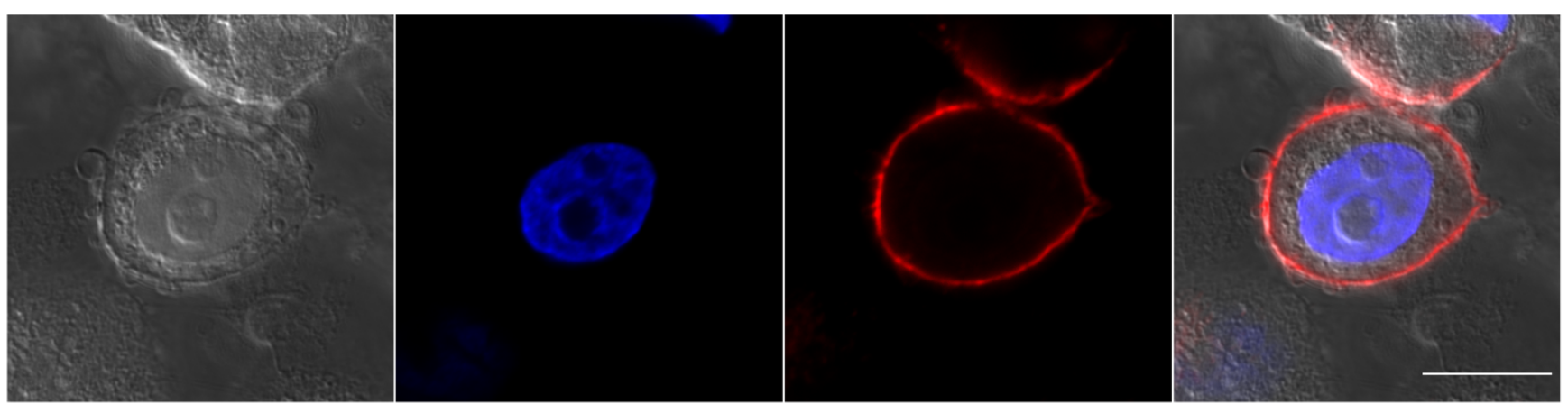

Figure 8

Confocal microscopic visualization confirming the localization of the HER2 IgY-SWNT complex on the cell membrane of SK-BR-3 cells. From left to right, the panels are the brightfield image, DAPI channel image showing the nucleus, quantum dot (QD) channel image showing fluorescence from the HER2 IgY-SWNT complex, and an overlay of the three. The white bar represents $10 \mu \mathrm{m}$. 
spectroscopic technologies for deep tissue imaging [39], SWNTs functionalized with antibody specific for tumor cell receptors may be exploited for in vivo specific detection of cancer cells at early stages.

The present study demonstrates very high specificity of the HER2 IgY-SWNT complexes for HER2-expressing cancer cells, indicating the potential usefulness of the IgY antibody for selective targeting of cancer cells. IgY antibodies offer many advantages over their mammalian IgG counterparts in terms of both production and biochemical and immunological properties. IgY antibodies can be isolated in large quantities from egg yolk using simple separation methods; the non-invasive production method also brings the great benefit concerning the welfare of the immunized animals [42]. IgY antibodies can also be used to avoid interference in immunological assays caused by the human complement system, rheumatoid factors, human anti-mouse IgG antibodies (HAMA) or human and bacterial Fc-receptors [43]. Similarly, for clinical use as antibody-based therapeutics, they neither activate mammalian complement nor interact with mammalian Fc receptors that could mediate inflammatory responses [44]. Despite these advantages, the application of IgY antibodies in research and medicine has been very limited [45]. Oral administration of IgY antibodies have shown great promise as immunotherapy for the prevention and treatment of enteric, respiratory, and dental infections in humans and animals [44-47]. As eggs are normal dietary components, there is practically no risk of toxic side effects of oral administration of IgY antibodies [44,46]. However, the phylogenetic distance between birds and mammals implies potential concerns over the immunogenicity of IgY antibodies in human. So far, there has been no report on intravenous administration of IgY antibodies in human and the associated immune responses. Nevertheless, concerns over IgY immunogenicity in human should be completely cleared out before any clinical application of IgY should be attempted. The results presented here and in a previous study [26] may bring more attention to this class of antibodies and promote studies on the immunogenicity of IgY preparations in human.

Temperature measurement of the IgY-SWNT complex solution at the nanotube concentration of $4 \mathrm{mg} / \mathrm{L}$ showed an increase of $\sim 14^{\circ} \mathrm{C}$ in the bulk solution, indicating the temperature rise of the surrounding environment would not cause harm to normal cells that do not bind to the SWNT-containing complex in the short time period (2 min). On the other hand, the same result also hinted that the thermal destructive effect to cancer cells must be microscopic rather than macroscopic. We hypothesize that temperature rise in the nanoscale vicinity of individual nanotubes can be dramatic. The sharp local temperature increase may cause damage to subcellular structures such as cell membranes ultimately leading to cell death. The ability to directly measure temperature of an individual nanoparticle will help to validate the hypothesis, and such an endeavor is currently underway [48].

The method described here for selective cancer cell destruction differs from the previously published ones $[7,20-22]$ in that our method does not require internalization of SWNTs into tumor cells. HER2 is a transmembrane glycoprotein with the receptor motif extended outside the cell membrane [49]. The reason for the lack of internalization of the SWNT complex by the cancer cells after binding to the cell surface receptor is not known; however, it is likely due to the surface chemistry of the SWNTs used here $[27,32]$. It has been reported the surface chemistry has a profound impact on the cellular uptake of nanoparticles such as quantum dots [50]. Although the exact mechanism may differ for various nanoparticles, the surface dependent cellular uptake may be a common phenomenon for all nanoparticles [51]. It is very important to note that the functionalization method used in the current study is different from those published previously where internalization of SWNTs after binding to the cell surface receptors have been reported $[7,20,22]$. In the study by Chakravarty et al. [21], cellular localization of SWNTs after incubation with cancer cells was not reported.

The method described here for selective photothermal ablation of cancer cells without the need of internalization by the cells has the advantage of being more easily extended to other types of cancer cells over agents that need internalization, as cellular internalization is not always achievable with all cancer types. Many cancer cells overexpress specific tumor markers (receptors) on their surface for which IgY antibody with high specificity and sensitivity can be developed. Thus, the IgY-SWNT complex, as exemplified in this study by the anti-HER2 IgY antibody, has the potential to become a novel, generic modality for detection and therapy of various cancer types. Our next step is to evaluate the pharmacokinetics, biodistribution, cytotoxicity and activity of such IgYSWNT complexes in vivo using animal models.

\section{Conclusion}

Our current work exploited two unique optical properties of SWNTs - very strong Raman signals and very strong NIR absorbance. We constructed a HER2 IgY-SWNT complex by covalently functionalizing SWNTs with anti-HER2 IgY antibody to impart to SWNTs the high specificity and sensitivity of the IgY antibody. The resultant complex was successfully used in vitro for both detection and selective destruction of HER2-expressing breast cancer cells. Raman signal from cancer cells was detected at the single-cell level. A uniqueness of this dual-function agent is that it does not require internalization by the cancer cells in 
order to achieve the selective photothermal ablation, thus offering the advantage of being more easily extended to other types of cancer cells. However, further research is needed before these findings can be translated into clinical trials.

\section{Competing interests}

The authors declare that they have no competing interests.

\section{Authors' contributions}

YX conceived of the study, designed and carried out most of the experimental work, coordinated the project, analyzed the data, and drafted the manuscript. XG participated in the design of the study, in the IgY antibody design and production, performed data analysis, and drafted the manuscript. OT carried out HER2 IgY-SWNT complex preparation and characterization, and analyzed the data. ST and AU participated in the Raman spectrometry studies. RDH participated in confocal imaging studies. REC and CTA participated in NIR irradiation and temperature measurement studies. SM prepared the SWNT samples. RS participated in HER2 IgY-SWNT complex preparation. PDW and SS participated in the design of the study and critically revised the manuscript. HH participated in the design of the study, supervised the HER2 IgY-SWNT complex preparation and characterization, and helped to draft the manuscript. All authors read and approved the final manuscript.

\section{Acknowledgements}

We thank Joseph Hodges and Kristen Steffens of NIST for their help with the laser radiation apparatus. This work was supported by $\mathrm{NCl}$-Early Detection Research Network joint NIST-Biochemical Science Division Interagency Agreement \#YI CN500 I and in part by National Science Foundation (NSF) Grant \#CHE-075020I. The contribution of CTA was supported partly by the New York State Office of Science, Technology, and Academic Research. Certain commercial equipment or materials are identified in this paper in order to specify adequately the experimental procedures. Such identification does not imply recommendation or endorsement by the National Institute of Standards and Technology, nor does it imply that the materials or equipment identified are necessarily the best available for the purpose.

\section{References}

I. Peer D, Karp JM, Hong S, Farokhzad OC, Margalit R, Langer R: Nanocarriers as an emerging platform for cancer therapy. Nat Nanotechnol 2007, 2:75 I-760.

2. Sapra P, Allen TM: Ligand-targeted liposomal anticancer drugs. Prog Lipid Res 2003, 42:439-462.

3. Hirsch LR, Gobin AM, Lowery AR, Tam F, Drezek RA, Halas NJ, West JL: Metal nanoshells. Ann Biomed Eng 2006, 34:I5-22.

4. Yang W, Thordarson P, Gooding JJ, Ringer SP, Braet F: Carbon nanotubes for biological and biomedical applications. Nanotechnology 2007, 18:4I2001.

5. Chen RJ, Bangsaruntip S, Drouvalakis KA, Kam NW, Shim M, Li Y, Kim W, Utz PJ, Dai H: Noncovalent functionalization of carbon nanotubes for highly specific electronic biosensors. Proc Natl Acad Sci USA 2003, 100:4984-4989.

6. Narayan RJ, Jin C, Menegazzo N, Mizaikoff B, Gerhardt RA, Andara M, Agarwal A, Shih CC, Shih CM, Lin SJ, Su YY: Nanoporous hard carbon membranes for medical applications. J Nanosci Nanotechnol 2007, 7:1486-1493.
7. Kam NW, O'Connell M, Wisdom JA, Dai H: Carbon nanotubes as multifunctional biological transporters and near-infrared agents for selective cancer cell destruction. Proc Natl Acad Sci USA 2005, 102: II600-II605.

8. Radomski A, Jurasz P, Alonso-Escolano D, Drews M, Morandi M, Malinski T, Radomski MW: Nanoparticle-induced platelet aggregation and vascular thrombosis. Br J Pharmacol 2005, 146:882-893.

9. Li X, Peng Y, Ren J, Qu X: Carboxyl-modified single-walled carbon nanotubes selectively induce human telomeric i-motif formation. Proc Natl Acad Sci USA 2006, 103:19658-19663.

10. Zhang LW, Zeng L, Barron AR, Monteiro-Riviere NA: Biological interactions of functionalized single-wall carbon nanotubes in human epidermal keratinocytes. Int J Toxicol 2007, 26:103-113.

II. Asuri P, Bale SS, Pangule RC, Shah DA, Kane RS, Dordick JS: Structure, function, and stability of enzymes covalently attached to single-walled carbon nanotubes. Langmuir 2007, 23:|23|8-12321.

12. Kam NWS, Dai H: Carbon nanotubes as intracellular protein transporters: generality and biological functionality. J Am Chem Soc 2005, 127:6021-6026.

13. Singh R, Pantarotto D, McCarthy D, Chaloin O, Hoebeke J, Partidos $C D$, Briand JP, Prato M, Bianco A, Kostarelos K: Binding and condensation of plasmid DNA onto functionalized carbon nanotubes: toward the construction of nanotube-based gene delivery vectors. J Am Chem Soc 2005, 127:4388-4396.

14. Liu Y, Wu DC, Zhang WD, Jiang X, He CB, Chung TS, Goh SH, Leong $\mathrm{KW}$ : Polyethylenimine-grafted multiwalled carbon nanotubes for secure noncovalent immobilization and efficient delivery of DNA. Angew Chem Int Edn Engl 2005, 44:4782.

15. Kam NW, Liu Z, Dai H: Functionalization of carbon nanotubes via cleavable disulfide bonds for efficient intracellular delivery of siRNA and potent gene silencing. J Am Chem Soc 2005, 1 27: I2492-I 2493.

16. Jorio A, Saito R, Dresselhaus G, Dresselhaus MS: Determination of nanotubes properties by Raman spectroscopy. Philos Transact A Math Phys Eng Sci 2004, 362:23 I I-2336.

17. Liu Z, Cai W, He L, Nakayama N, Chen K, Sun X, Chen X, Dai H: In vivo biodistribution and highly efficient tumor targeting of carbon nanotubes in mice. Nat Nanotechnol 2007, 2:47-52.

18. Keren S, Zavaleta C, Cheng Z, de la Zerda A, Gheysens O, Gambhir SS: Noninvasive molecular imaging of small living subjects using Raman spectroscopy. Proc Natl Acad Sci USA 2008, 105:5844-5849.

19. Liu Z, Li X, Tabakman SM, Jiang K, Fan S, Dai H: Multiplexed multicolor Raman imaging of live cells with isotopically modified single walled carbon nanotubes. I Am Chem Soc 2008, 130: I3540-1354|.

20. Shao N, Lu S, Wickstrom E, Panchapakesan B: Integrated molecular targeting of IGFIR and HER2 surface receptors and destruction of breast cancer cells using single wall carbon nanotubes. Nanotechnology 2007, 18:315101.

21. Chakravarty P, Marches R, Zimmerman NS, Swafford AD, Bajaj P, Musselman IH, Pantano P, Draper RK, Vitetta ES: Thermal ablation of tumor cells with antibody-functionalized single-walled carbon nanotubes. Proc Natl Acad Sci USA 2008, 105:8697-8702.

22. Zhou F, Xing D, Ou Z, Wu B, Resasco DE, Chen WR: Cancer photothermal therapy in the near-infrared region by using single-walled carbon nanotubes. J Biomed Opt 2009, I 4:02 I009.

23. McDevitt MR, Chattopadhyay D, Kappel BJ, Jaggi JS, Schiffman SR, Antczak C, Njardarson JT, Brentjens R, Scheinberg DA: Tumor targeting with antibody-functionalized, radiolabeled carbon nanotubes. I Nucl Med 2007, 48: I I80-1 I89.

24. Gabizon AA: Pegylated liposomal doxorubicin: metamorphosis of an old drug into a new form of chemotherapy. Cancer Invest 200I, 19:424-436.

25. Zhang WW: The use of gene-specific IgY antibodies for drug target discovery. Drug Discov Today 2003, 8:364-37I.

26. Xiao Y, Gao X, Gannot G, Emmert-Buck MR, Srivastava S, Wagner PD, Amos MD, Barker PE: Quantitation of HER2 and telomerase biomarkers in solid tumors with IgY antibodies and nanocrystal detection. Int J Cancer 2008, I 22:2I78-2 I86.

27. Wang Y, lqbal Z, Mitra S: Rapidly functionalized, water-dispersed carbon nanotubes at high concentration. J Am Chem Soc 2006, I 28:95-99. 
28. Papadopoulos NG, Dedoussis GV, Spanakos G, Gritzapis AD, Baxevanis CN, Papamichail M: An improved fluorescence assay for the determination of lymphocyte-mediated cytotoxicity using flow cytometry. J Immunol Methods 1994, I77: I0I-I II.

29. Bankfalvi A, Boecker W, Reiner A: Comparison of automated and manual determination of HER2 status in breast cancer for diagnostic use: a comparative methodological study using the Ventana BenchMark automated staining system and manual tests. Int J Oncol 2004, 25:929-935.

30. Xiao Y, Telford WG, Ball JC, Locascio LE, Barker PE: Semiconductor nanocrystal conjugates, FISH and pH. Nat Methods 2005, 2:723.

31. Xiao Y, Barker PE: Semiconductor nanocrystal probes for human metaphase chromosomes. Nucleic Acids Res 2004, 32:e28.

32. Huang W, Taylor S, Fu K, Lin Y, Zhang D, Hanks TW, Rao AM, Sun YP: Attaching proteins to carbon nanotubes via diimide-activated amidation. Nano Lett 2002, 2:3 II-3I4

33. O'Connell MJ, Bachilo SM, Huffman CB, Moore VC, Strano MS, Haroz EH, Rialon KL, Boul PJ, Noon WH, Kittrell C, Ma J, Hauge RH, Weisman RB, Smalley RE: Band gap fluorescence from individual single-walled carbon nanotubes. Science 2002, 297:593-596.

34. Bachilo SM, Strano MS, Kittrell C, Hauge RH, Smalley RE, Weisman RB: Structure-assigned optical spectra of single-walled carbon nanotubes. Science 2002, 298:236 I-2366.

35. Dyke CA, Tour JM: Solvent-free functionalization of carbon nanotubes. J Am Chem Soc 2003, I 25: I I 56-II 57.

36. Hudson JL, Casavant MJ, Tour JM: Water-soluble, exfoliated, nonroping single-wall carbon nanotubes. J Am Chem Soc 2004, 1 26: III58-11159.

37. Choo-Smith LP, Edwards HG, Endtz HP, Kros JM, Heule F, Barr H, Robinson JS Jr, Bruining HA, Puppels GJ: Medical applications of Raman spectroscopy: from proof of principle to clinical implementation. Biopolymers 2002, 67:1-9.

38. Nijssen A, Koljenovi S, Bakker Schut TC, Caspers PJ, Puppels GJ: Towards oncological application of Raman spectroscopy. Biophotonics 2009, 2:29-36.

39. Matousek P, Stone N: Emerging concepts in deep Raman spectroscopy of biological tissue. Analyst 2009, 134:1058-1066.

40. Schulmerich MV, Cole JH, Dooley KA, Morris MD, Kreider JM, Goldstein SA, Srinivasan S, Pogue BW: Noninvasive Raman tomographic imaging of canine bone tissue. J Biomed Opt 2008 i3:020506.

41. Srinivasan S, Schulmerich M, Cole JH, Dooley KA, Kreider JM, Pogue BW, Morris MD, Goldstein SA: Image-guided Raman spectroscopic recovery of canine cortical bone contrast in situ. Opt Express 2008, 16:12190-12200.

42. Tini M, Jewell UR, Camenisch G, Chilov D, Gassmann M: Generation and application of chicken egg-yolk antibodies. Comp Biochem Physiol A Mol Integr Physiol 2002, I 3 I :569-574.

43. Carlander D, Stålberg J, Larsson A: Chicken antibodies: a clinical chemistry perspective. Ups J Med Sci 1999, 104:179-89.

44. Carlander D, Kollberg H, Wejåker PE, Larsson A: Peroral immunotherapy with yolk antibodies for the prevention and treatment of enteric infections. Immunol Res 2000, 2I:I-6.

45. Schade R, Calzado EG, Sarmiento R, Chacana PA, PorankiewiczAsplund J, Terzolo HR: Chicken egg yolk antibodies (IgY-technology): a review of progress in production and use in research and human and veterinary medicine. Altern Lab Anim 2005, 33:129-154.

46. Larsson A, Carlander D: Oral immunotherapy with yolk antibodies to prevent infections in humans and animals. Ups Med Sci 2003, 108:129-140.

47. Mine $Y$, Kovacs-Nolan J: Chicken egg yolk antibodies as therapeutics in enteric infectious disease: a review. J Med Food 2002, 5:159-169

48. Avedisian CT, Cavicchi RE, McEuen PL, Zhou X: Nanoparticles for cancer treatment: role of heat transfer. Ann N Y Acad Sci 2009, 1 161:62-73.

49. Akiyama T, Sudo C, Ogawara H, Toyoshima K, Yamamoto T: The product of the human c-erbB-2 gene: a 185 -kilodalton glycoprotein with tyrosine kinase activity. Science 1986 232: $1644-1646$.

50. Clift MJ, Rothen-Rutishauser B, Brown DM, Duffin R, Donaldson K, Proudfoot L, Guy K, Stone V: The impact of different nanoparticle surface chemistry and size on uptake and toxicity in a murine macrophage cell line. Toxicol Appl Pharmacol 2008, 232:418-427.

5I. Chavanpatil MD, Khdair A, Panyam J: Nanoparticles for cellular drug delivery: mechanisms and factors influencing delivery. J Nanosci Nanotechnol 2006, 6:265I-2663.

\section{Pre-publication history}

The pre-publication history for this paper can be accessed here:

\section{http://www.biomedcentral.com/1471-2407/9/351/pre} pub
Publish with Biomed Central and every scientist can read your work free of charge

"BioMed Central will be the most significant development for disseminating the results of biomedical research in our lifetime. "

Sir Paul Nurse, Cancer Research UK

Your research papers will be:

- available free of charge to the entire biomedical community

- peer reviewed and published immediately upon acceptance

- cited in PubMed and archived on PubMed Central

- yours - you keep the copyright 